\title{
Results from the Fermilab 1.5 M Model Magnet Program
}

M. Lamm, R. Bossert, J. Carson, S. Delchamps, T. Jaffery, W. Kinney, W. Koska, J. Ozelis, J. Strait and M. Wake

Fermi National Accelerator Laboratory

P.O. Box 500, Batavia, Illinois 60510

R. Sims and M. Winters

SSC Laboratory

2550 Beckleymeade Ave., Dallas, Texas 75237

April 1992

Presented at the Fourth Annual IISSC, New Orlean, LA, March 4-6, 1992. 


\section{Disclaimer}

This report was prepared as an account of work sponsored by an agency of the United States Government. Neither the United States Government nor any agency thereof, nor any of their employees, makes any warranty, express or implied, or assumes any legal liability or responsibility for the accuracy, completeness, or usefulness of any information, apparatus, product, or process disclosed, or represents that its use would not infringe privately owned rights. Reference herein to any specific commercial product, process, or service by trade name, trademark, manufacturer, or otherwise, does not necessarily constitute or imply its endorsement, recommendation, or favoring by the United States Government or any agency thereof. The views and opinions of authors expressed herein do not necessarily state or reflect those of the United States Government or any agency thereof. 


\title{
RESULTS FROM THE FERMILAB 1.5 M MODEL MAGNET PROGRAM
}

\author{
M.J. Lamm1, R. Bossert1, J. Carson'1,S. Delchamps', T.S. Jaffery1 , \\ W. Kinney1, W. Koska1, J. Ozelis1, R. Sims2, J. Strait1, M.Wake1 \\ and $M$. Winters ${ }^{2}$ \\ 1Fermi National Accelerator Laboratory \\ P.O. Box 500 \\ Batavia, Il 60510 \\ 2SSC Laboratory, Fermilab/SSCL Magnet Project \\ Fermi National Accelerator Laboratory \\ P.O. Box 500 \\ Batavia, Il 60510
}

\begin{abstract}
A series of model SSC collider dipole magnets (50 mm aperture, $1.5 \mathrm{~m}$ magnetic length) are being built and tested at Fermilab. The early magnets have been built according to the Fermilab baseline design. The magnets are precursors to the full length $15 \mathrm{~m}$ models to be used in the Accelerator Systems String Test at the SSCL. All magnets are instrumented with voltage taps for quench localization and with strain gages to measure stresses and deflections in the coil and support structure. Measurements are made during assembly, cooldown, excitation, and warmup. Comparisons are made between data and design expectations, and magnet behavior is correlated with changes in the magnet design and assembly methods.
\end{abstract}

\section{INTRODUCTION}

Tests have been performed at Fermilab on $50 \mathrm{~mm}$ aperture $1.5 \mathrm{~m}$ long model magnets built at Fermilab for the SSC project. Because of the reduced longitudinal scale of the magnets $1.5 \mathrm{~m}$ vs 15 . $\mathrm{m}$ ) and because these magnets are tested in a vertical dewar (and hence need not be placed in their own cryostat), it is possible to build and test magnets approximately 3 times faster than the longer magnets and at a much reduced cost. This allows the program to validate many design features in a timely fashion which in turn may be incorporated into the long magnet program.

Table 1 is a summary of the eight $50 \mathrm{~mm}$ model magnets that have been constructed to date. These magnets incorporate the features of the Fermilab full length baseline design $1,2,3,4$. The inner(outer) coils are made of 30 (23) strand NbTi cable with 6 micron filament diameter and $\mathrm{Cu}: \mathrm{SC}$ ratio of 1.49. The copper field shaping wedges are insulated either with glass-epoxy tape and Kapton or Kapton only. The $1.52 \mathrm{~mm}$ thick stainless steel collar laminations are locked in place using tapered brass keys. The outer coil is insulated from the collars by 5 layers of $0.13 \mathrm{~mm}$ Kapton insulation. On some magnets, quench protection heater strips are placed between these layers. The results of heater tests have been reported elsewhere5. The inner-outer coil splice is located extemal to the high field body region, and is supported along with the magnet end by G-10 collets and an 


\begin{tabular}{|c|c|c|c|c|}
\hline $\begin{array}{l}\text { Magnet } \\
\text { Name }\end{array}$ & $\begin{array}{l}\text { Variation of } \\
\text { Fermilab Baseline }\end{array}$ & $\begin{array}{c}\text { Collar } \\
\text { Shimming } \\
(\operatorname{mm}) \\
\text { Inner/Outer }\end{array}$ & $\begin{array}{c}\text { Post-Yoke } \\
\text { Stress } \\
\text { (MPa) } \\
\text { Inner/Outer }\end{array}$ & $\begin{array}{l}\text { Pre-Stress } \\
\text { Loss with } \\
\text { Cooldown } \\
\text { (MPa) }\end{array}$ \\
\hline DSA321 & $\begin{array}{l}\text { Stainless Steel } \\
\text { End Can }\end{array}$ & $0 . / 0$ & $62 . / 86$. & $-19 . /-14$ \\
\hline DSA322 & $\begin{array}{c}\text { Assembly } \\
\text { Experiments Only }\end{array}$ & & & \\
\hline DSA323 & $\begin{array}{l}\text { Stainless Steel } \\
\text { End can }\end{array}$ & $0 . / 0$ & 52.772. & $-30 . /-10$ \\
\hline DSA324 & $\begin{array}{l}\text { Aluminum } \\
\text { End Can }\end{array}$ & $.13 / . .13$ & $76 . / 60$. & $-33 . /-8$ \\
\hline DSA326 & $\begin{array}{l}\text { Aluminum } \\
\text { End Can }\end{array}$ & $0 . / 0$ & $69 . / 56$ & $-37 . /-23$ \\
\hline DSA327 & $\begin{array}{c}\text { Assembly } \\
\text { Experiments only }\end{array}$ & & & \\
\hline DSA328 & $\begin{array}{c}\text { Kapton Only } \\
\text { Wedge Insulation } \\
\text { Inner Coil Only }\end{array}$ & $.09 /-.13$ & $70 . / 45$ & $-36 . /-9$ \\
\hline DSA329 & $\begin{array}{c}\text { Kapton Only } \\
\text { Wedge Insulation }\end{array}$ & $.09 / 0$ & $69 . / 39$. & $\begin{array}{l}\text { Presently } \\
\text { Under Test }\end{array}$ \\
\hline
\end{tabular}

Table 1. Summary of Fermilab Constructed $1.5 \mathrm{~m}$ Model Magnets.

aluminum or stainless steel cylindrical can. The yoke consists of vertically split low carbon high quality steel laminations. A stainless steel shell surrounds the yoke and is seam welded longitudinally.

The magnet is instrumented with voltage taps at each coil splice. Additionally, the first two current blocks nearest the the inner coil pole are instrumented for quench localization. Strain gage transducers 6 are located in the collars to measure azimuthal stress between the collars and the coils. Gages are also located on the surface of the shell to measure the stress due to welding, cooldown, and the force transferred by friction from the coil during excitation. End force gages measure the force of the coil on the end plate due to differential thermal contraction during cooldown and the Lorentz force due to magnet excitation.

\section{EXPERIMENTAL DETAILS}

Collar strain gages were monitored during the collaring and yoking process. The design postyoke stress is $70 \pm 14 \mathrm{MPa}$ for the inner coils and $56 \pm 14$ for the outer coils. This coil stress is adjusted by adding or subtracting Kapton insulation at the pole as well as modifying the molding fixture. As shown in Table 1, the desired inner stress is obtained except in magnet DSA323. For DSA321 and DSA323, the outer stress was systematically higher than design but was adjusted lower on subsequent magnets. Magnet measurements were performed after collaring and then again after yoking using the BNL B2 Mole measuring system ${ }^{7}$. The system consists of $0.6 \mathrm{~m}$ tangential and dipole bucking coils rotating at $0.31 \mathrm{~Hz}$. The voltages were read by fast sampling DVMs. The resultant voltages are analyzed using an FFT algorithm.

Cold measurements are performed in a $3.1 \mathrm{~m}$ vertical dewar of boiling helium. Magnet temperatures of $3.0 \mathrm{~K}$ to $4.35 \mathrm{~K}$ are achieved by varying the boiling helium bath pressure. Strain gages and voltage taps, as well as dewar temperature, pressure and helium liquid level are monitored through a DEC MicroVax II computer. Magnetic measurements are performed by inserting warm probes into a stainless steel anti-cryostat, which is in turn inserted into the bore of the magnet. The dipole field strength is measured using a Rawson-Lush field meter and has an accuracy of approximately 1 part in 5000 . Field harmonics are measured using Morgan and tangential coils rotated at $6 \mathrm{~Hz}$. The $46 \mathrm{~cm}$ active length Morgan coil was used on the earlier tests ${ }^{8}$, and was later 
replaced with a $25 \mathrm{~cm}$ active length tangential coil. The resultant voltages are processed using a V/F based data acquisition system. The Morgan coil data has windings up to the decapole only, thus no transverse centering through 16 pole or 20 pole elimination is possible. For these tests only the allowed b2 and b4 are reported. Magnetic measurements are performed as a function of excitation current, and as a function of longitudinal position at $5 \mathrm{kA}$. The strain gage data are recorded in increments of magnet excitation squared. The magnet is repeatedly ramped to quench at $16 \mathrm{~A} / \mathrm{s}$ to establish a quench plateau at $4.35 \mathrm{~K}, 4.2 \mathrm{~K}$ and $3.8 \mathrm{~K}$. Additional quenches are performed at $4.35 \mathrm{~K}$ at ramp rates up to $300 \mathrm{~A} / \mathrm{s}$. AC loss measurements were performed on DSA323, DSA324 and DSA328. Each magnet was tested through at least two thermal cycles in order to study retraining.

Tests of five of these magnets(DSA321, DSA323, DSA324, DSA326, DSA328) have been completed. DSA329 has not yet been cold tested. Two magnets (DSA322, DSA327) have been used for collaring experiments, and will not be cold tested.

\section{RESULTS}

\section{Quench Performance}

The quench performance at $4.35 \mathrm{~K}$ (first thermal cycle) and $3.8 \mathrm{~K}$ (performed on either first or second thermal cycle) is shown in Figure 1. For all quenches the magnet is ramped at $16 \mathrm{~A} / \mathrm{s}$ from zero excitation current. The quench velocity for such plateau quenches is typically $80 \mathrm{~m} / \mathrm{s}^{9}$. With the exception of the first quench of DSA321, these magnets exhibit no training at $4.35 \mathrm{~K}$. The quenches occur in the straight section of the inner pole tum which is the high field region of the coil. The training quench in DSA321 occurred in the outer coil and is probably attributable to a manufacturing enror 10. No training quenches are observed during subsequent thermal cycles. At $3.8 \mathrm{~K}$ less than one training quench was observed on average. The exception to this was DSA324 which exhibited three quenches in the outer coil.

During the initial test of DSA323, the magnet was found to quench unpredictably at approximately $3 \mathrm{kA}$ on the down ramp only. The quenches occurred in the pole turn of one of the inner coils at the return end. The magnet was partially disassembled and the end cylinder was removed. It was discovered that the coil end saddles were not all the same length. Thus, the shorter coil might not be properly supported axially through the cylindrical end can. The end saddle lengths were adjusted, the magnet was reassembled and retested. Unfortunately, down ramp quenches were also found during this second test. Further studies are needed to understand this problem.

Figure 2 shows the ramp rate dependence of the quench current. At ramp rates less than 25$50 \mathrm{~A} / \mathrm{s}$ the quench current is insensitive to the ramp rate. The quenches occur in the high field region of the conductor. For two magnets, DSA321 and DSA323, this small ramp dependence extends to $200 \mathrm{~A} / \mathrm{s}$ and beyond. DSA 323 quenches above $200 \mathrm{~A} / \mathrm{s}$ occur in the ramp splice near the pole turn. For magnets with more severe ramp rate dependence, the high ramp rate quenches occur in a less instrumented portion of the magnet, towards the midplane. The high ramp rate quench location near the midplane is expected because there the magnetic field direction is most perpendicular to the wide cable face, thus facilitating inter-strand eddy currents.

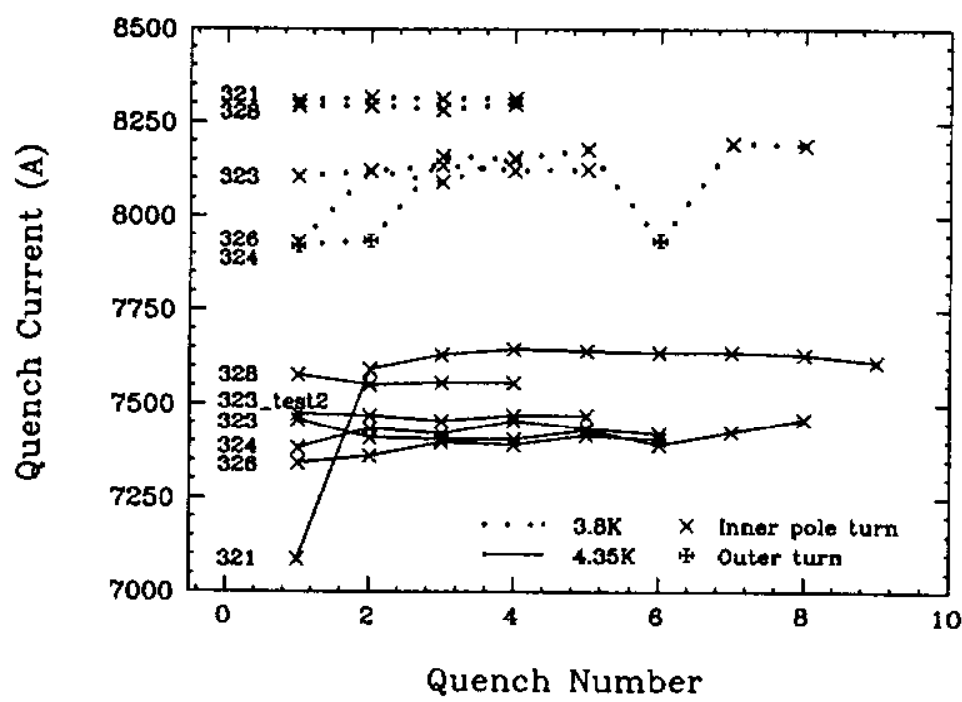

Figure 1. Quench history for first thermal cycle. 


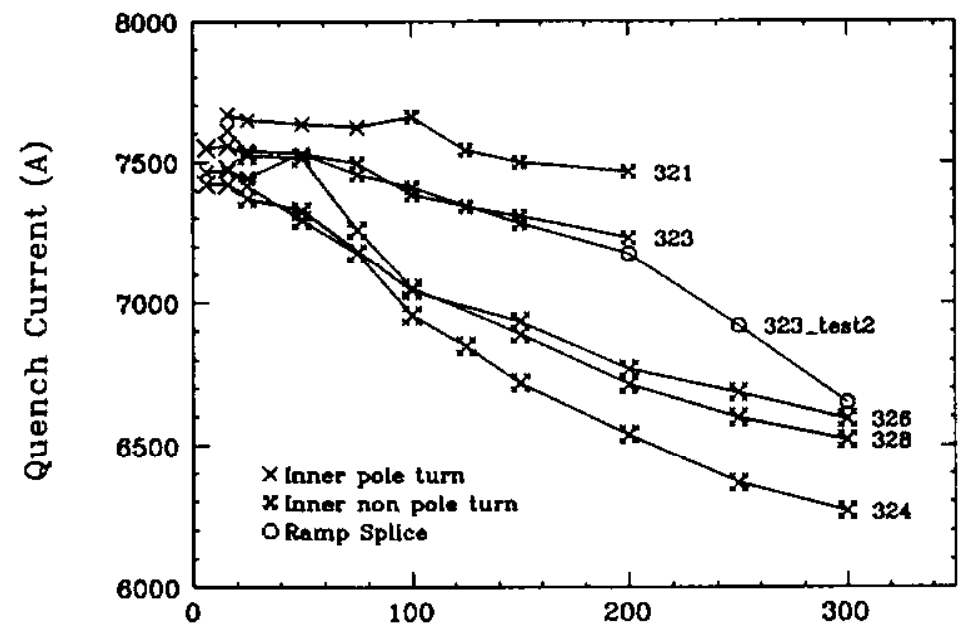

Ramp Rate (A/S)

Figure 2. Quench current as a function of ramp rate at $4.35 \mathrm{~K}$

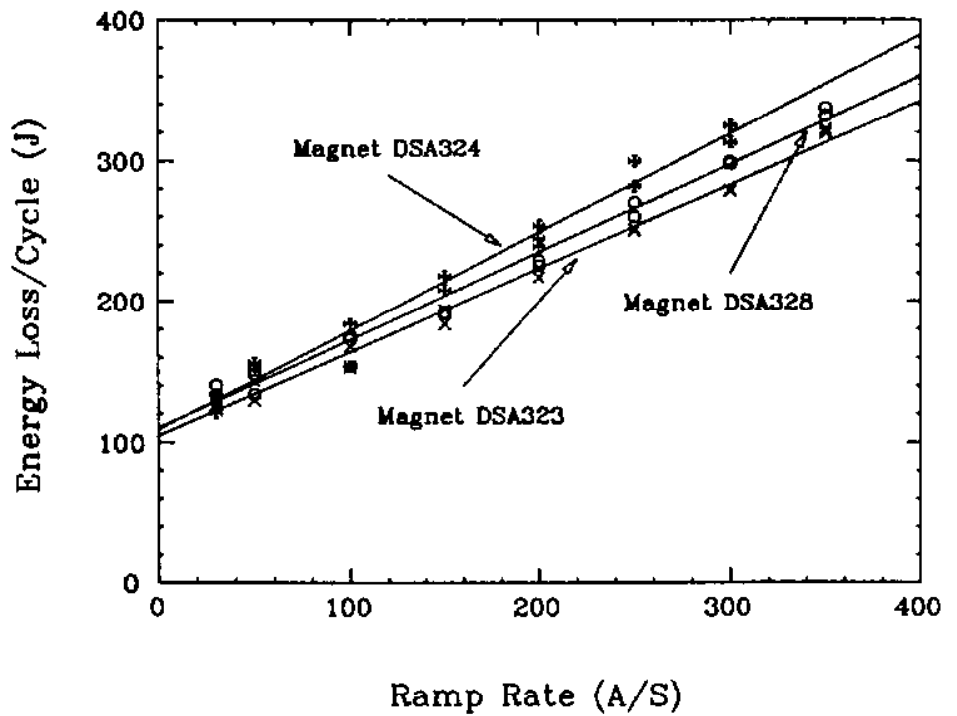

Figure $3 \mathrm{AC}$ loss as a function of ramp rate. The magnet is cycled between $0.5 \mathrm{kA}$ and $5 \mathrm{kA}$ Solid lines are least square fit to data. Slope of lines are $0.703,0.624$, and $0.594 \mathrm{~J} / \mathrm{A} / \mathrm{S}$ for DSA324, DSA328, and, DSA323 respectively.

\section{AC Loss Measurements}

For three magnets (DSA323, DSA324, DSA328) the AC loss as a function of ramp rate was measured using fast digitizing DVM's to measure the magnet voltage and current 11,12 . Figure 3 shows the AC loss as a function of ramp rate using a $0.5 \mathrm{kA}$ to $5.0 \mathrm{kA}$ ramp cycle. The data from each magnet are fit to a straight line. The extrapolated value at $\mathrm{dI} / \mathrm{dt}=0$ is the $\mathrm{AC}$ loss due to iron and superconductor magnetization. All three lines extrapolate to the same value to within measurement errors at $\mathrm{dI} / \mathrm{dt}=0$. This is expected since these magnets have the same iron contribution and are made with similar conductor. The difference in slope among the magnets is due to the different levels of eddy current loss. A comparison of Figure 2 with Figure 3 shows that there is a correlation between eddy current loss and quench current degradation at high ramp rate. The variation of $A C$ loss as well as ramp rate dependence among these similar magnets (DSA323 and DSA324 are made with conductor from the same reel) is an interesting phenomenon that is under study. 


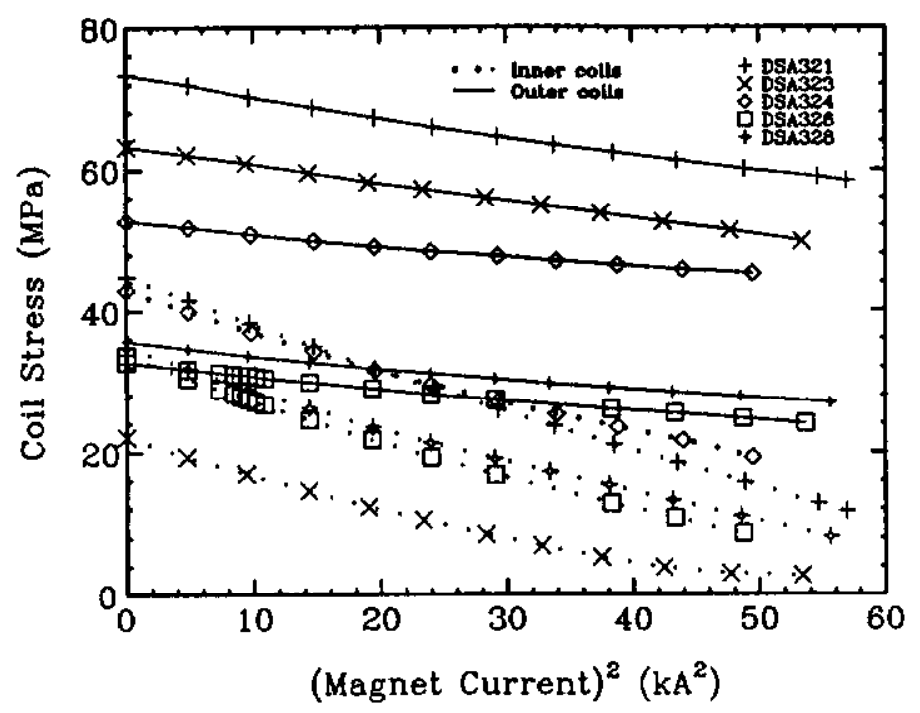

Figure 4 Average coil stress as a function of excitation current squared.

\section{Mechanical Measurements}

Figure 4 shows the average prestress for inner and outer coils as a function of excitation current squared (12). As shown in Table 1, each magnet loses 30 (15) MPa of coil stress during cool down to LHe temperatures for inner(outer) coils. With the exception of DSA323, both inner and outer coils show adequate prestress; no unloading is observed even at the highest $\mathrm{I}^{2}$. The slope of stress vs $\mathrm{I}^{2}$ is approximately linear. A linear relationship between increasing end force and $\mathrm{I}^{2}$ is also observed (not shown). The average end force at $7.5 \mathrm{kA}$ is $15 \mathrm{kN}$, which implies that approximately 90 percent of the the coil Lorentz force at this current is transferred to the collar/yoke/shell by friction.

\section{Magnetic Measurements}

Table 2 summarizes the magnetic measurement at room temperature and in atmospheric pressure boiling helium. The cold measurements are an average of the readings taken at $2 \mathrm{kA}$ from the up and down portion of a ramp cycle with maximum excitation current greater than $7.0 \mathrm{kA}$. Only b2 and b4 are reported for DSA321 and DSA324 because only data from the Morgan coil is available. For all magnets except DSA321, the probe active length is positioned longitudinally at least $20 \mathrm{~cm}$ away from the strain gage transducers. This is because the strain gage block becomes magnetic upon excitation at cyrogenic temperatures and contributes significantly to b2 and b4 at $2 \mathrm{kA}$ excitation current. For DSA321 the gage pack was located at the magnet's longitudinal center. Thus it was not possible to take data without the influence of the gage pack. For this magnet the effect of the gage pack is estimated from studies on a later magnet 13 .

For the room temperature measurements, the data are an average of $\pm 10 \mathrm{~A}$ measurements in order to eliminate the effect of any external magnetic field such as the earth's magnetic field. The data are recorded at several longitudinal positions. However, we present only the data taken at the same longitudinal location as the corresponding to cold measurement.

With the exception of pole shims and differences in copper wedge insulation, the variations in harmonics are due to measuring and manufacturing errors. To estimate the warm and cold random error, several data points were taken at the same longitudinal location for one magnet (DSA326). The random errors are small compared to the magnet to magnet variation. The effect of Kapton pole shimming which should affect only the allowed harmonics is estimated using field calculations ${ }^{14}$. On the whole, the RMS deviation of the harmonics are all within the required SSC random error tolerances. For many of the harmonics the systematic values are larger than the SSC systematic tolerance, even after correcting for the effects of pole shimming as shown. For b8, the present design has approximately +0.05 units built in to aid in the centering corrections. The large variation in b2 may be due in part to the distribution in cable thickness. The average shim corrected b2 value for DSA321-6 (glass-epoxy tape insulated wedges) is $2.1 \pm$.6 compared to $0.5 \pm 3$ for DSA328-9 
HARMONICS (UNITS@10 mm)

\begin{tabular}{|c|c|c|c|c|c|c|c|c|c|}
\hline Pole & 321 & 323 & 324 & 326 & 328 & 329 & $\begin{array}{l}326 \\
\text { Ran. }\end{array}$ & $\begin{array}{l}\text { SSC } \\
\text { Sys. }\end{array}$ & $\begin{array}{l}\text { SSC } \\
\text { Ran. }\end{array}$ \\
\hline b2 Warm & 2.952 & 1.378 & 1.762 & 2.190 & 0.069 & 1.796 & 0.082 & 0.80 & 1.15 \\
\hline Cold & 3.2 & 1.497 & 1.935 & 2.243 & 0.427 & & 0.025 & & \\
\hline Warm corrected & 2.95 & 1.38 & 1.67 & 2.19 & 0.21 & 0.87 & & & \\
\hline b4 Warm & 0.327 & 0.215 & 0.186 & 0.350 & 0.255 & 0.079 & 0.015 & 0.08 & 0.22 \\
\hline Cold & 0.22 & 0.134 & 0.040 & 0.284 & 0.099 & & 0.005 & & \\
\hline warm corrected & 0.33 & 0.22 & 0.34 & 0.35 & 0.39 & 0.20 & & & \\
\hline b6 Warm & -0.075 & -0.082 & -0.036 & -0.069 & -0.027 & -0.037 & 0.007 & 0.013 & 0.02 \\
\hline Cold & & -0.046 & & -0.030 & -0.026 & & 0.002 & & \\
\hline Warm corrected & -0.075 & -0.082 & -0.051 & -0.069 & -0.041 & -0.055 & & & \\
\hline b8 Warm & 0.047 & 0.056 & 0.052 & 0.056 & 0.058 & 0.046 & 0.005 & 0.01 & 0.01 \\
\hline Cold & & 0.045 & & 0.049 & 0.038 & & 0.011 & & \\
\hline Warm corrected & 0.047 & 0.056 & 0.056 & 0.056 & 0.061 & 0.049 & & & \\
\hline b10 Warm & 0.023 & 0.015 & 0.018 & 0.015 & 0.018 & 0.011 & 0.003 & & \\
\hline Cold & & 0.016 & & 0.012 & 0.014 & & 0.000 & & \\
\hline bl Warm & -0.071 & 0.095 & -0.090 & 0.065 & -0.272 & -0.467 & 0.119 & 0.04 & 0.5 \\
\hline Cold & & 0.192 & & 0.374 & -0.132 & & 0.042 & & \\
\hline b3 Warm & 0.027 & -0.011 & -0.090 & 0.101 & 0.010 & 0.045 & 0.017 & 0.026 & 0.16 \\
\hline Cold & & 0.058 & & 0.080 & -0.041 & & 0.018 & & \\
\hline b5 Warm & 0.022 & -0.021 & -0.032 & -0.023 & 0.025 & 0.012 & 0.012 & 0.05 & 0.02 \\
\hline Cold & & -0.022 & & -0.004 & 0.005 & & 0.004 & & \\
\hline b7 Warm & -0.004 & -0.005 & 0.000 & 0.004 & -0.002 & 0.001 & 0.002 & 0.05 & 0.01 \\
\hline Cold & & 0.000 & & 0.032 & 0.000 & & 0.005 & & \\
\hline b9 Warm & 0.002 & 0.015 & -0.002 & 0.006 & 0.010 & 0.005 & 0.005 & & \\
\hline Cold & & 0.000 & & 0.041 & 0.000 & & 0.003 & & \\
\hline al Warm & -2.151 & 0.407 & -0.003 & 1.025 & -0.966 & -0.666 & 0.133 & 0.04 & 1.25 \\
\hline Cold & & -0.332 & & 0.964 & 0.041 & & 0.033 & & \\
\hline a2 Warm & 0.104 & 0.027 & 0.427 & 0.689 & 0.099 & 0.287 & 0.082 & 0.32 & 0.35 \\
\hline Cold & & 0.588 & & 0.575 & 0.094 & & 0.006 & & \\
\hline a3 Warm & -0.024 & 0.021 & 0.190 & 0.086 & 0.092 & -0.039 & 0.056 & 0.26 & 0.32 \\
\hline Cold & & -0.151 & & -0.002 & 0.156 & & 0.017 & & \\
\hline a4 Warm & 0.097 & -0.067 & 0.044 & 0.055 & 0.023 & 0.040 & 0.022 & 0.01 & 0.05 \\
\hline Cold & & 0.046 & & 0.023 & -0.019 & & 0.013 & & \\
\hline a5 Warm & 0.043 & -0.020 & 0.049 & 0.015 & 0.021 & -0.027 & 0.014 & 0.005 & 0.05 \\
\hline Cold & & -0.009 & & 0.021 & 0.027 & & 0.007 & & \\
\hline a6 Warm & 0.004 & 0.003 & -0.008 & -0.016 & -0.023 & 0.010 & 0.006 & 0.005 & 0.008 \\
\hline Cold & & 0.006 & & -0.017 & -0.001 & & 0.011 & & \\
\hline a7 Warm & -0.008 & 0.035 & 0.000 & 0.004 & -0.010 & -0.001 & 0.002 & 0.005 & 0.01 \\
\hline Cold & & 0.004 & & 0.012 & 0.000 & & 0.018 & & \\
\hline a8 Warn & 0.019 & 0.010 & 0.003 & 0.006 & 0.001 & 0.003 & 0.008 & 0.005 & 0.008 \\
\hline Cold & & 0.004 & & -0.007 & 0.003 & & 0.005 & & \\
\hline a9 Warm & 0.001 & 0.009 & -0.002 & 0.016 & 0.000 & 0.002 & 0.004 & & \\
\hline Cold & & 0.000 & & 0.014 & 0.000 & & 0.001 & & \\
\hline a10 Warm & 0.004 & -0.014 & -0.002 & 0.008 & 0.005 & 0.002 & 0.005 & & \\
\hline Cold & & 0.002 & & -0.005 & 0.000 & & 0.001 & & \\
\hline & & & & & & & & \multicolumn{2}{|l|}{ Predicted } \\
\hline TF collar & 0.795 & 0.794 & 0.794 & 0.793 & 0.794 & 0.796 & 0.0002 & 0.794 & \\
\hline Warm & 1.042 & 1.043 & 1.043 & 1.042 & 1.041 & 1.041 & 0.0002 & 1.045 & \\
\hline Cold & & 1.042 & 1.043 & 1.044 & 1.042 & & 0.002 & 1.045 & \\
\hline
\end{tabular}

Table 2 Measured warm and cold harmonics. Room temperature measurements are averages of \pm 10 amps. Cold harmonics are average of up ramp-down ramp value at $2 \mathrm{kA}$ for Imax $>7 \mathrm{kA}$ cycle. Cold Transfer function measured with the Rawson Lush Field meter at $3 \mathrm{kA}$. For b2, b4 ,b6, b8 warm harmonics corrected for pole shims are also presented. 


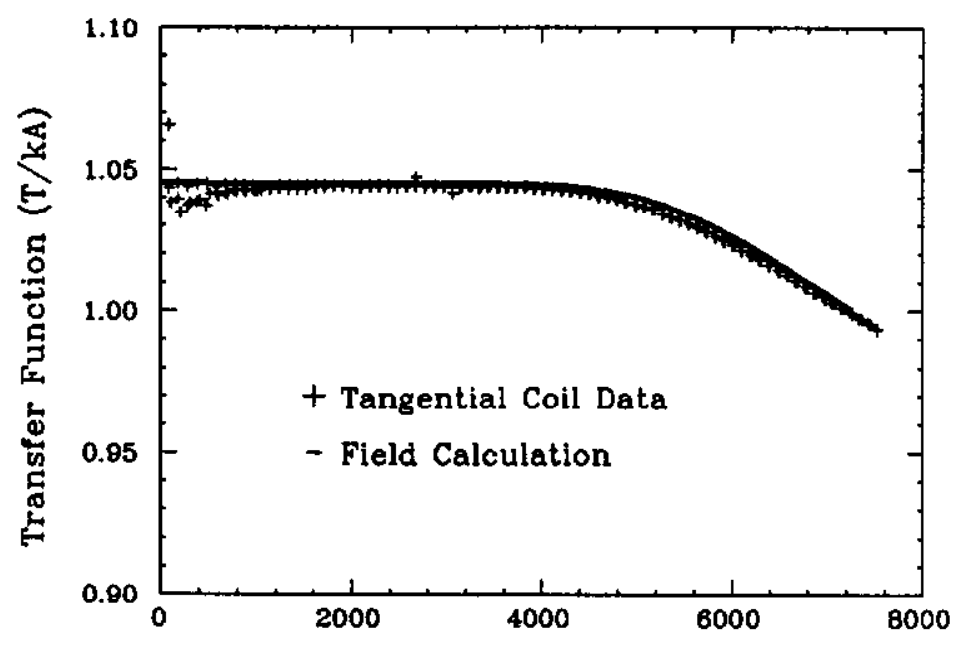

Current (A)

Figure 5. Measured and predicted transfer function vs excitation current.

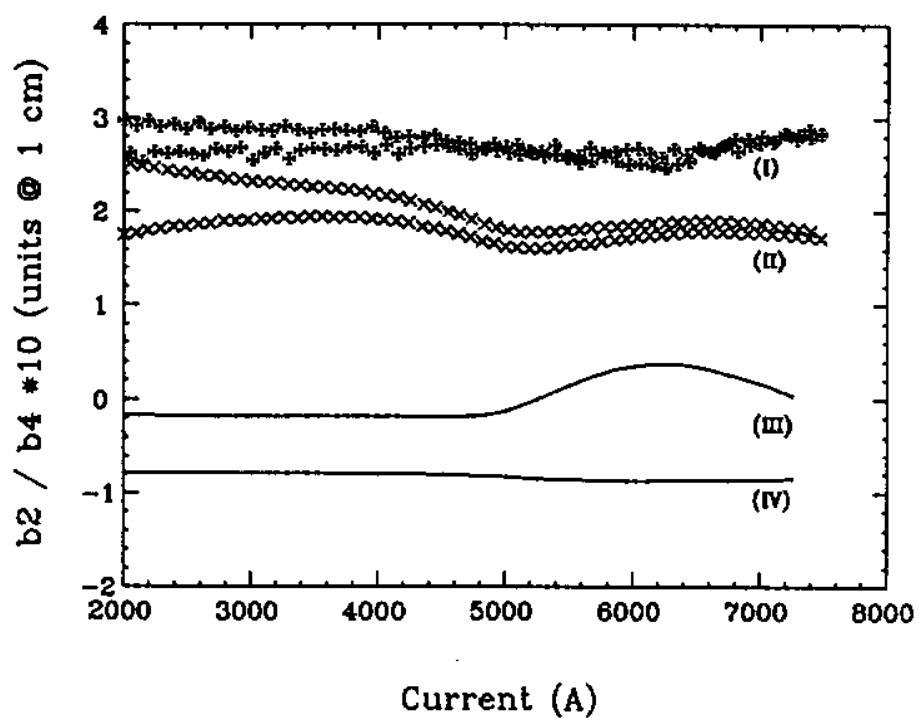

Figure 6. Measured and predicted harmonics vs excitation current. (I) b2 from DSA326 (II) b4 from DSA326, (III) Predicted Iron Saturation for b4, (IV) predicted Iron Saturation for b2

(Kapton only insulated wedges). It is estimated that a $.005 \mathrm{~mm}$ displacement of the middle tum of the inner coil towards the midplane (pole angles kept constant and all tum thickness adjusted linearly) would change $b 2$ by +1.1 units 15 .

There is generally good correlation between warm and cold harmonics. For b2 and b4 (where we have the most statistics) the RMS of the warm-cold distribution is less than 20 percent of the SSC random error tolerance. Thus the warm measurements should be a good indication of the magnet's cold geometric harmonics at fields where the iron saturation effects are negligible.

Also included in Table 2 is a comparison of the measured transfer function for the collared coils and warm and cold assembled magnets with prediction 4 . The cold measurements are taken at $3 \mathrm{kA}$ excitation current with the Rawson-Lush field meter. The effect of iron saturation at higher fields is shown in Figures 5 and 6 . Figure 5 shows the transfer function for DSA326, measured with one of the dipole windings on the tangential probe. Above $4 \mathrm{kA}$, the iron saturation becomes significant. 
For all magnets, both warm and cold, the measured value is systematically lower than predicted. Figure 6 shows b2 and b4 as a function of excitation current, for currents above $2 \mathrm{kA}$. The dip in both distributions at $4 \mathrm{kA}$ is due to iron saturation in the poles, the subsequent rise is due to iron saturation at the midplane. Cutouts are included in the iron yoke midplane to balance these two saturation effects. The predicted b2 and b4 are also shown. b2 is expected to vary by approximately 0.6 units. The measured variation is smaller. It is interesting to note that the shape of $b 2$ is different for Fermilab and BNL designed model dipoles. This is likely due to a collar alignment notch which is located in the midplane of the vertically split Fermilab magnets and in the pole of the horizontally split BNL magnets.

\section{CONCLUSION}

Tests have been performed on several Fermilab-built $50 \mathrm{~mm}$ aperture $1.5 \mathrm{~m}$ long model magnets. The quench performance has been very good, with few training quenches. All quenches at the nominal $16 \mathrm{~A} / \mathrm{s}$ ramp rate exceed the SSC design operating current by at least $600 \mathrm{amps}$. There is a correlation between AC eddy current energy loss and ramp rate dependence of the quench current.

All magnets exhibit good mechanical behavior. With the exception of the DSA323 inner coil, there is adequate stress to prevent unloading during magnet excitation.

The warm and cold harmonics have been measured. Though the statistics are limited, the RMS variation appears to be well within the SSC specifications. There is a good correlation between warm and cold harmonics. There is good agreement in shape of the transfer function, though the warm and cold transfer functions are systematically lower than predicted. The measured variation b2 due to iron saturation is smaller than predicted.

\section{ACKNOWLEDGMENTS}

We would like to thank the staffs of the Fermilab Superconducting Magnet Production Group and the Superconducting R \&D Test Facility for their assistance in performing these studies.

\section{REFERENCES}

1. J. Strait et al., "Mechanical Design of the 2D Cross-section of the SSC Collider Dipole Magnet", Proc. of the 1991 IEEE Par. Acc. Conf., San Francisco,Vol 4, pp. 2176-8, 1991.

2. S. Delchamps et al., "SSC Collider Dipole Magnet End Mechanical Design", Proc. of the 1991 IEEE Par. Acc. Conf, San Francisco, Vol 4, pp. 2285-8, 1991.

3. R. C. Gupta et al., "SSC 50 mm Dipole Cross Section", Supercollider 3, pp.587-599 1991.

4. E.G.Pewitt (ed), "50 mm Collider Dipole Magnet Requirements and Specifications", Fermilab 1991.

5. C. Haddock et al., "SSC Dipole Quench Protection Heater Development", Proc. of the 12th Int. Conf. on Mag. Tech., June 1991, Leningrad, USSR.

6. C. L. Goodzeit et al., "Measurement of Intemal Forces in Superconducting Accelerator Magnets with Strain Gage Transducers", IEEE Trans. Magn., Vol. 25, pp. 1463-1468, 1989.

7. G. Ganetis et al., "Field measuring probe for SSC magnets", Proc. 1987 IEEE Particle Accel. Conf., Washington D.C., 1987 , p.1393.

8. M.J. Lamm et al., "Magnetic Field Measurements of 1.5 Meter Model SSC Collider Dipole Magnets at Fermilab", Proc. of the 12th Int. Conf. on Mag. Tech., June 1991, Leningrad, USSR.

9. T. Jaffery, "Quench Summary of DSA324", Fermilab Technical Support Intemal Note TS-SSC 91-175, Sept. 1991.

10. M. Wake et al., "Quench behavior of $1.5 \mathrm{~m}$ model SSC collider dipole magnets at Fermilab", Proc. of the 12th Int. Conf. on Mag. Tech., June 1991, Leningrad, USSR.

11. M.J. Lamm et al. "Bipolar and Unipolar Tests of $1.5 \mathrm{~m}$ Model SSC Collider Dipole Magnets at Fermilab", Proc. of the 1991 IEEE Par. Acc. Conf.,San Francisco,Vol 4, pp. 2191-4, 1991.

12. J. Ozelis, "Status of AC Loss Measurements of $1.5 \mathrm{~m}$ Model Dipole Magnets at Fermilab" Fermilab Technical Support Internal Note TS-SSC 91-205.

13. S. Delchamps "Effect of strain gage blocks on normal sextupole moment in DSA321 and DSA323, Fermilab Technical Support Internal Note TS-SSC 91-104, 1991.

14. R. Gupta, private communication.

15. R. Gupta, "Effect of the Azimuthal Variation in the Cable Thickness on the Field Harmonics in SSC 50 mm Dipole Cross Section", BNL Magnet Division Note 379-1(SSC-MD-264), 1991. 